\title{
GENERATION OF MICROBUBBLES THROUGH SINGLE LOOP AND DOUBLE LOOP FLUID OSCILLATOR FOR PHOTOBIOREACTOR AERATION
}

\author{
Muhammad Ilham Rizaldi ${ }^{1}$, Arif Rahman ${ }^{1}$, Deendarlianto ${ }^{2}$, \\ Nining Betawati Prihantini ${ }^{3}$, Nasruddin ${ }^{1 *}$ \\ ${ }^{1}$ Department of Mechanical Engineering, Faculty of Engineering, Universitas Indonesia, Kampus UI \\ Depok, Depok 16424, Indonesia \\ ${ }^{2}$ Department of Mechanical and Industrial Engineering, Faculty of Engineering, Universitas Gadjah \\ Mada, Yogyakarta 55281, Indonesia \\ ${ }^{3}$ Department of Biology, Faculty of Mathematics and Natural Sciences, Universitas Indonesia, \\ Kampus UI Depok, Depok 16424, Indonesia
}

(Received: August 2019 / Revised: October 2019 / Accepted: November 2019)

\begin{abstract}
Microbubbles are known for their many applications. Recently there has been new findings regarding the growth of susceptible microalgae through microbubble aeration. There are three methods used to generate microbubbles for this microalgae strain. Unfortunately, for some methods, the cost of generating microbubbles is still high. However, fluidic oscillators can be used to produce microbubbles at a reasonable cost. There are two types of fluid oscillators: single loop and double loop. This study determined the bubble size produced with these oscillators. Bubble size data was recorded using a high-speed camera at air flow rates of 6 LPM, 9 LPM, 12 LPM, and 15 LPM, and utilized $10 \mu \mathrm{m}$ microporous shafts as the diffuser. The data were processed using ImageJ software. The results showed that the size of the bubble using a single loop fluid oscillator was smaller than that of the double loop fluid oscillator. The smallest bubble size was obtained in a single loop fluid oscillator with an airflow of 6 LPM.
\end{abstract}

Keywords: Fluid oscillator; Microbubble; Photobioreactor

\section{INTRODUCTION}

The issues related to increased energy demand, environmental pollution and depletion of fossil fuels are considered very urgent: renewable and alternative fuels must replace fossil fuels while maintaining fresh air and ensuring energy security (Pham et al., 2018). Biodiesel is an alternative fuel that contains long chain fatty acids known as mono alkyl esters. It is predominantly a renewable, clean-burning fuel that is environmentally friendly, nontoxic, and free from harmful sulphur (Hidayat et al., 2018). The application of microalgae to biodiesel production has great potential: it has gained attention because it can produce oil in the cells of its body. The oil content in microalgae ranges from $20-50 \%$ and microalgae can exceed $80 \%$ of the weight of dry biomass (Rahman et al., 2019).

A lot of microalgae biomass can be cultivated by using photobioreactors. Using this method, microalgae conduct photosynthesis as they would in their natural habitat. The process of photosynthesis requires light and carbon dioxide as energy sources for the growth of microalgae. During the process of photosynthesis in photobioreactors, microalgae absorbs the content of

\footnotetext{
*Corresponding author's email: nasruddin@eng.ui.ac.id, Tel. +62-21-7863504, Fax. +62-21-7270050 Permalink/DOI: https://dx.doi.org/10.14716/ijtech.v10i7.3691
} 
carbon dioxide, which dissolves in the medium such as Bold Basal Medium (BBM), Medium Cyanobacteria TAPS (CT) and NPK (Nitrogen Phospor Potassium) medium. A good medium for the transfer process between carbon dioxide and microalgae requires microbubbles.

A microbubble isdefined as a bubble with a diameter ofless than one millimeter (50-200 $\mu \mathrm{m})$ (Juwana et al., 2019; Deendarlianto et al., 2015). Microbubbles have advantages across many applications due to their bubble size. For example, they have been used in wastewater treatment (Rehman et al., 2015;Budhijanto et al.), biomolecular separation (Lye et al., 2001) and microorganism aeration (Hanotu et al., 2016). Their small size yields advantages, such as higher surface to volume ratio, which provide higher mass transfer rates. Another advantage of microbubbles is slow rise velocity, which allows more substances to dissolve in the medium due to its residence time (Zheng et al., 2018).

Microbubbles have unique characteristics, such as high gas dissolution, low rising velocity, and high interfacial area (Deendarlianto et al., 2015). Recently, there has been a special case regarding the growth of susceptible microalgae strains using microbubbles. One method of generating microbubbles uses pumped water; however, this cannot be used to breed micro algae because it creates circulation. As a result, the strain would experience high shear stress due to the pumping action and would eventually decease. The only way to develop microbubbles without creating circulation involves pumping air through sparger in photobioreactor, and there are three methods of achieving this. The most common method uses compressed air, which flows through a specifically designed nozzle to generate small bubbles based on the cavitation principle. The second method uses ultrasonic sound waves to oscillate a needle tip following air coming through the water chamber, thus creating a continuous stream of tiny bubbles (Makuta et al., 2005). Unfortunately, both methods require high energy densities; this makes the operational cost of a photobioreactor quite high (Zimmerman et al., 2008). One possible low-cost method involves microbubble generation by oscillating the airflow using mechanical vibration. The bubbles generated will break off at a size that is close to the diameter of the hemisphericalcap.

A fluidic oscillator is a no moving part jet actuator that is able to oscillate airflow because of its special geometry. It has a low cost because it is easy to manufacture using the CNC (Computer Numerical Control) machining process and does not need frequent maintenance. There have been many reviews about the characteristics of fluidic oscillators. The most common types of fluidic oscillators are the double loop fluid oscillator and the single loop fluid oscillator, created by Warren and Spyropoulos (Warren, 1964;Spyropoulos, 1964). Recently, Tesar has made a modified model using both types that can achieve an oscillation frequency up to $\sim 200 \mathrm{~Hz}$ (Tesař et al., 2013;Zimmerman et al., 2011). However, no reviews have comprehensively studied bubble generation through fluidic oscillators using a microporous sparger as a diffuser. This study will investigate the bubble size produced by fluidic oscillators effectively.

\section{METHODOLOGY}

The setup of the experiment is shown in Figure 1. The test section used a rectangular prism filled with water $(15 \mathrm{~cm} \times 40 \mathrm{~cm} \times 40 \mathrm{~cm})$. The airflow consisted of compressed air with a pressure of 1 bar. This pressure was set to the minimum gauge pressure so the bubbles could break off from the diffuser. The airflow was controlled using a flow meter with flow variance tested at 6 LPM, 9 LPM, 12 LPM, and 15 LPM. The variations in volumetric airflow values were chosen because they met the minimum flow needed for air to go through the fluidic oscillator based on experiment that has been done before. Two models of Tesar fluidic oscillators were used (Figure 2 and Figure 3). After flowing through the oscillator, air then passed through the diffuser. The diffuser was a microporous sparger manufactured by Shenzen Hengko Technology with a pore diameter size of $10 \mu \mathrm{m}$. 
Data was acquired through digital image analysis. The experimental apparatus featured a Nikon D5200 camera with 1/4000 shutter speed, ISO 6400 attached with a Nikon AF-S FX MicroNIKKOR Standard Macro Lens, set with a focal length of $85 \mathrm{~mm}$ and aperture of $2.5 \mathrm{~mm}$. This was used to capture the microbubbles. In the behind of the test section, a diffused layer was placed between the test section and a $50 \mathrm{~W}$ LED lamp. This photographic technique was used to get a sharper image of the bubbles. Before the experiment began, a ruler was placed inside the test section and on the sparger to calibrate the dimension of the object. To analysis the object, the dimension of the object must be converted to the pixel dimension using ImageJ software.

Images of the microbubbles were captured and then processed using ImageJ software. They were transformed using a bandpass filter to sharpen the edges of the bubbles. After a series of processes, they were finally transformed into binary images. These could be analyzed to determine the area and diameter of the bubbles. The bubbles were analyzed through a $20 \mathrm{~mm} \times$ $20 \mathrm{~mm}$ rectangular sample. This was completed 20 times for each image for more accurate results.

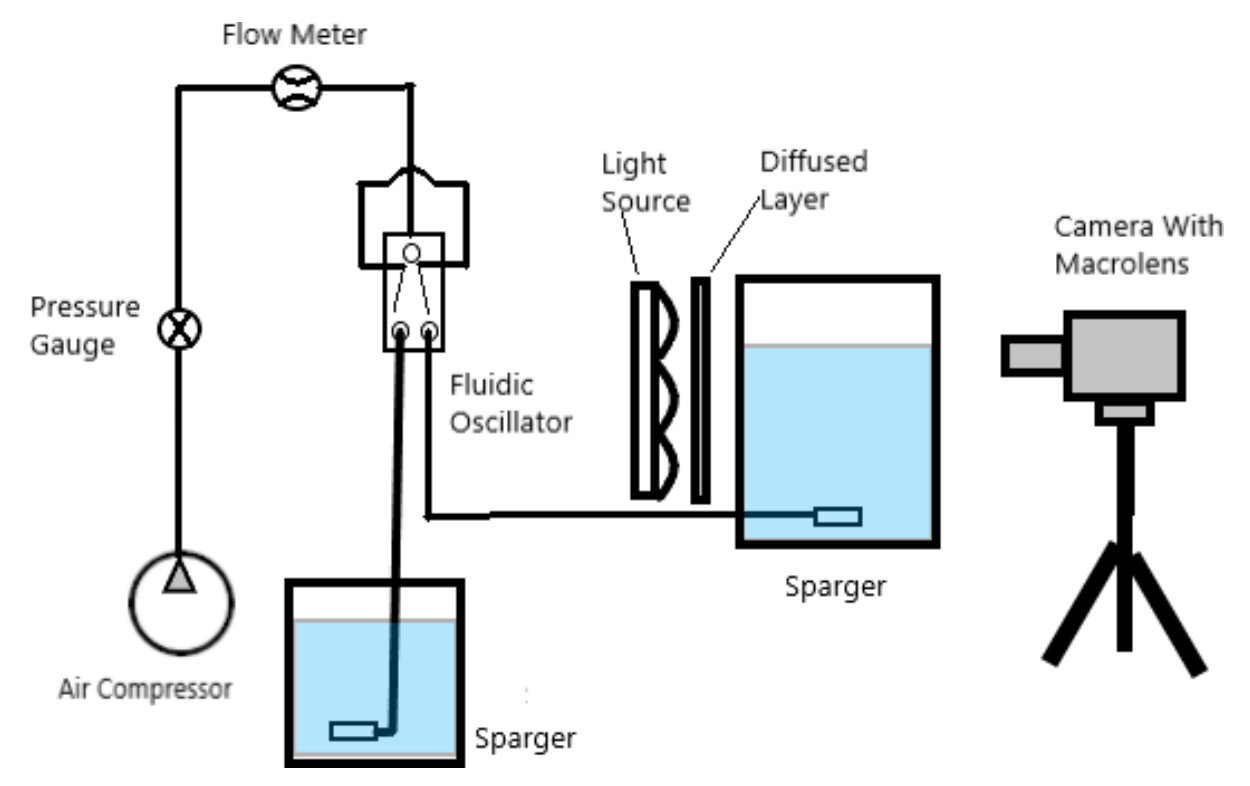

Figure 1 Schematic diagram of the apparatus used in this experiment

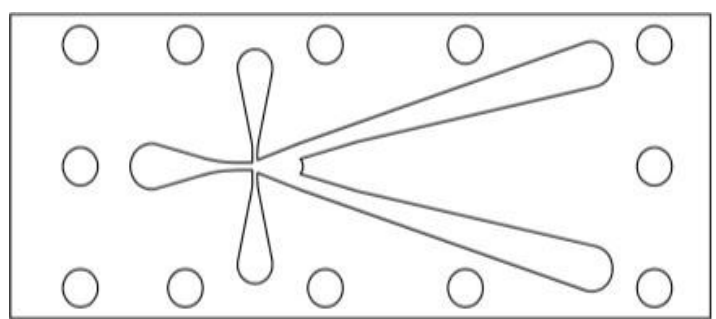

Figure 2 Single loop fluidic oscillator

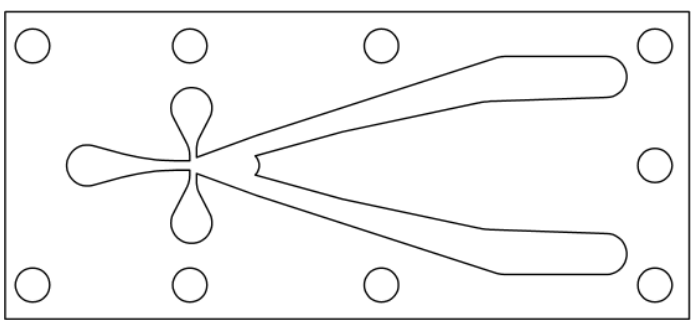

Figure 3 Double loop fluidic oscillator

\section{RESULTS AND DISCUSSION}

The processed images provided data on the size distribution of the microbubbles for each experiment variation. The bubble size data has been plotted with the amount of bubbles to understand the bubble density difference in each experiment. Figure 4 and Figure 5 show the difference between continuous flow bubble generation and oscillated flow bubble generation. It was found that oscillated flow yielded were smaller bubbles and a higher density of bubbles. 


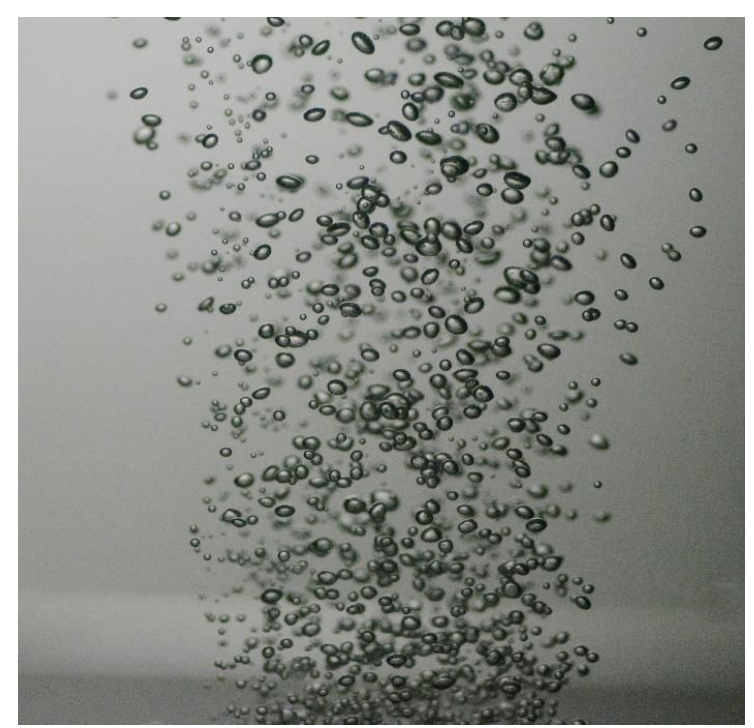

Figure 4 Continuous flow bubble generation

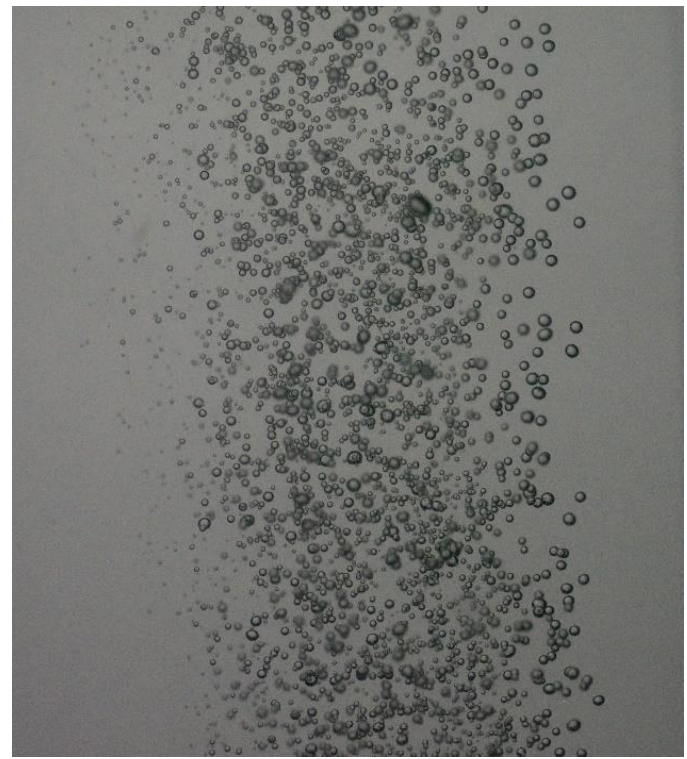

Figure 5 Oscillated flow bubble generation

The results of the bubbles generated by the double loop fluidic oscillator and single loop fluidic oscillator are shown in Figure 6. The bubble size distribution data was obtained through image processing.

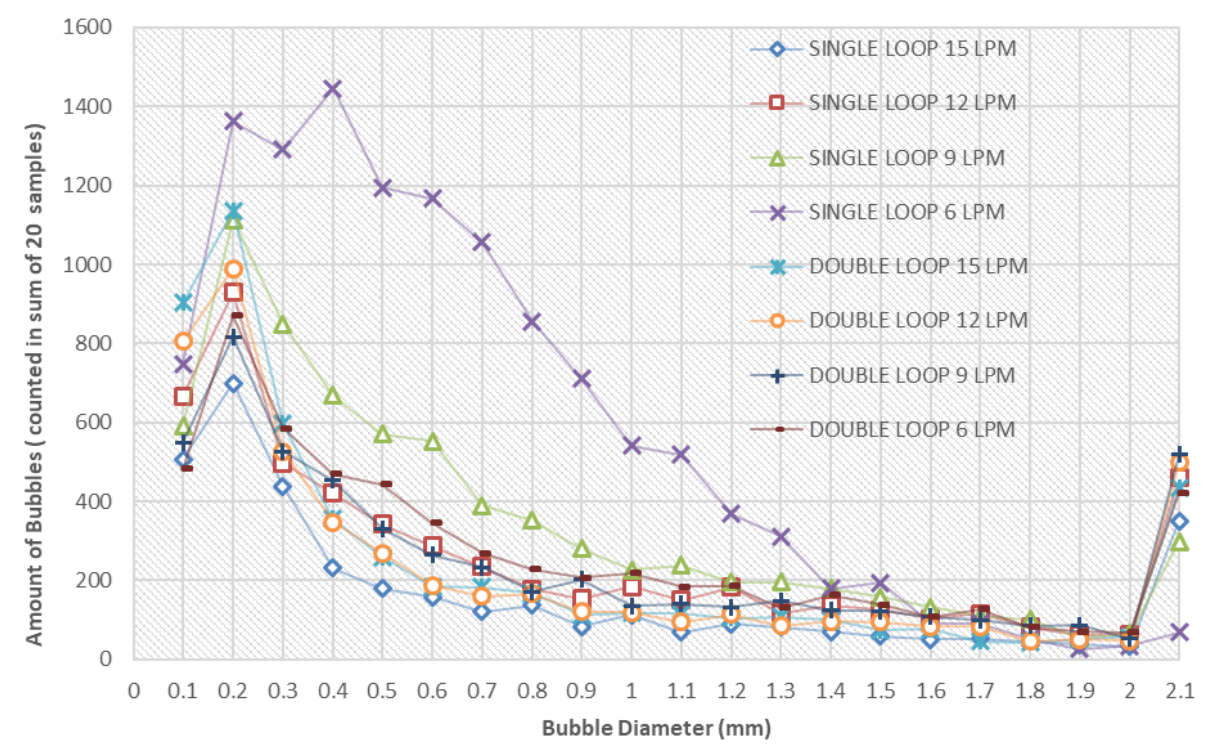

Figure 6 Bubble size distribution based on single loop and double loop fluidic oscillator with airflow variations

The bubbles were found to be evenly distributed in single loop fluidic oscillators with an airflow of 6 LPM while, for other airflow rates (9 LPM, 12 LPM, and 15 LPM), it was not evenly distributed (the quantity of bubbles larger than $2 \mathrm{~mm}$ increased). The bubble distribution in double loop fluidic oscillators was uneven. Each airflow rate had bubbles larger than $2 \mathrm{~mm}$ in diameter, which comprised over $5 \%$ of the total bubbles generated each run. Bubbles with a diameter larger than $2 \mathrm{~mm}$ were formed due to the union of bubbles from the previous bubble generation. Although the quantity of bubbles with a diameter greater than $2 \mathrm{~mm}$ increased, the quantity of bubbles with diameters smaller than 200 micronsal so increased with increased airflow. This increase in frequency caused the airflow to be oscillated faster, resulting in bubble sizes that were close to the sparger pore size. This is in accordance with the research conducted 
by Vaclav Tesar, which stated that higher oscillator frequencies yielded smaller bubble size (Tesař, 2014). However, the large quantity of air discharge caused a build up at the tip of the sparger which caused large bubbles being formed at the end of the sparger. Figure 7 displays this phenomenon.

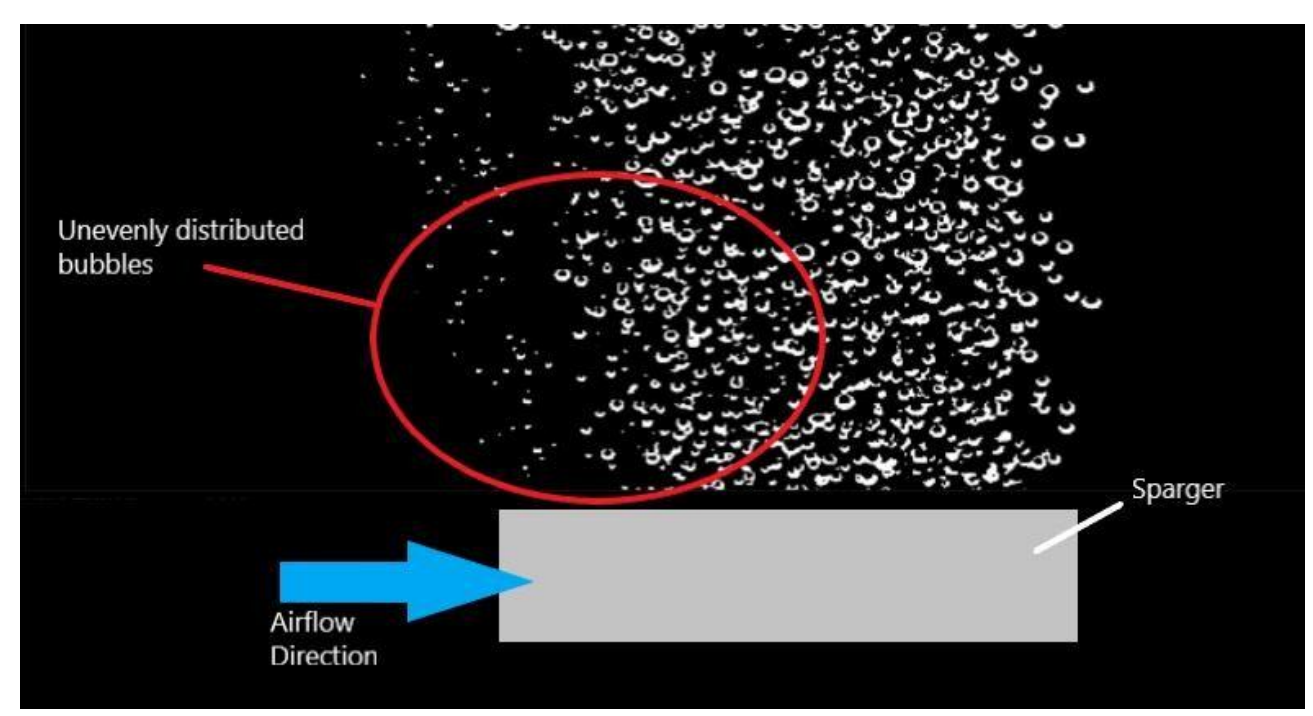

Figure 7 Unevenly distributed bubble size captured

By using the bubble size distribution data obtained from image processing, it can be processed to obtain bubble size, number of bubble and bubble size distribution. While to find out the average bubble diameter can be determined through the sauter mean diameter analysis and the bubble density of each area. The sauter mean diameter value is obtained using Equation 1.

$$
d_{s m}=\frac{\sum_{i=1}^{n} d_{i}^{3}}{\sum_{i=1}^{n} d_{i}^{2}}
$$

where $d_{s m}$ is sauter mean diameter $(\mathrm{mm}), d_{i}$ is bubble diameter $i(\mathrm{~mm})$ and $n_{i}$ is number of bubble sizes $i$ (no dimension).

The sauter mean diameter is obtained through visual data processing. The sauter mean diameters of bubbles in a single loop fluidic oscillator with airflow variations of 6 LPM, 9 LPM, 12 LPM and $15 \mathrm{LPM}$ were $1.10 \mathrm{~mm}, 1.97 \mathrm{~mm}, 3.04 \mathrm{~mm}$, and $3.43 \mathrm{~mm}$. The sauter mean diameters of bubbles in a double loop fluidic oscillator with the same air flow variations were $2.17 \mathrm{~mm}, 3.06$ $\mathrm{mm}, 4.98 \mathrm{~mm}$, and $4.86 \mathrm{~mm}$. The sauter mean diameter indicates that a higher flow rate resulted in a higher average bubble diameter. The relationship between the flow rate and the sauter mean diameter is shown in Figure 8.

The bubble density in each area was obtained by processing the visual data. The bubble densities yielded by a single loop fluidic oscillator with airflow rates of 6 LPM, 9 LPM, 12 LPM, and 15 LPM were 51.3 bubbles $/ \mathrm{cm}^{2}, 30.5$ bubbles $/ \mathrm{cm}^{2}, 22.88$ bubbles $/ \mathrm{cm}^{2}$, and 22.55 bubbles $/ \mathrm{cm}^{2}$. The bubble densities yielded by a double loop fluidic oscillator using the same airflow rates were 24.15 bubbles $/ \mathrm{cm}^{2}, 22.08$ bubbles $/ \mathrm{cm}^{2}, 20.79$ bubbles $/ \mathrm{cm}^{2}$, and 21.78 bubbles $/ \mathrm{cm}^{2}$. These values indicate that an increase in airflow rate results in increased bubble density. The bubbles fused and created larger-size bubbles. Moreover, this data shows that increased airflow yields in more frequent bubble fusion. The relationship between flow rate and bubble density is shown in Figure 9. 


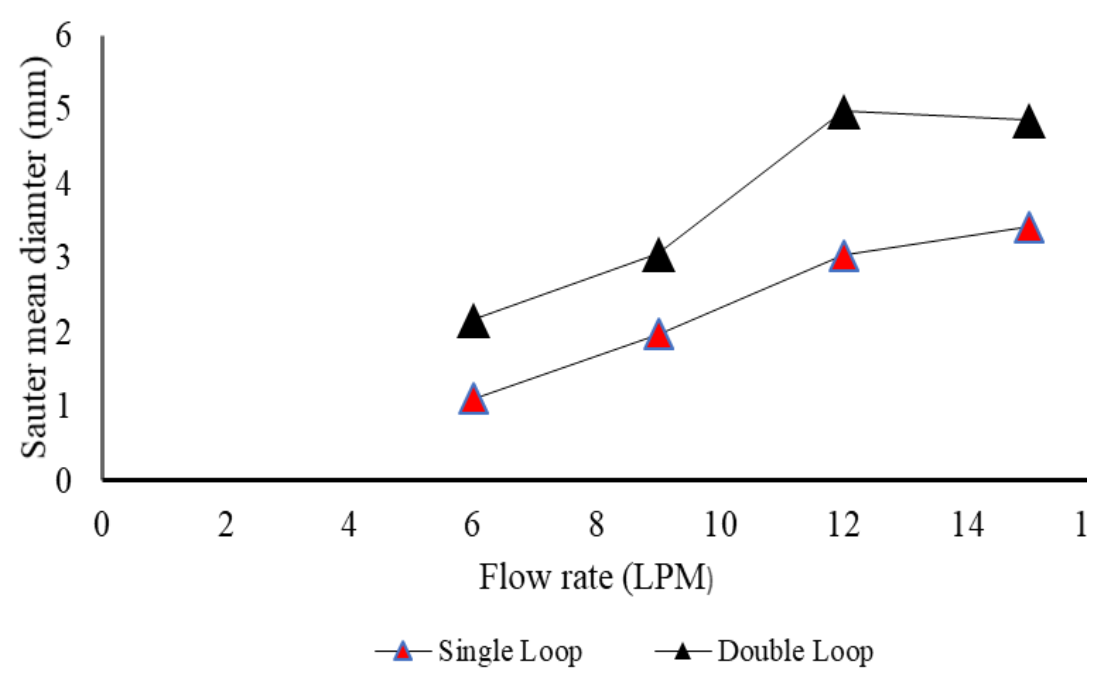

Figure 8 The relationship between flow rate and the sauter mean diameter

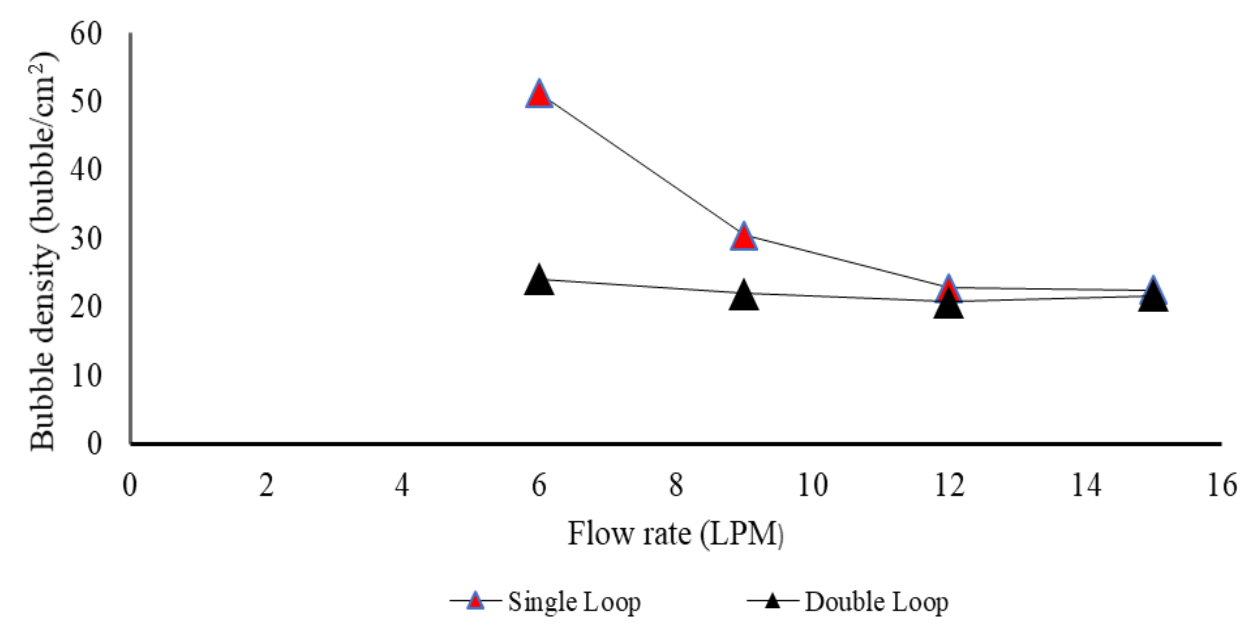

Figure 9 The relationship between flow rate and bubble density

\section{CONCLUSION}

In conclusion, airflow affects the characteristics of bubble size: a higher airflow results in more bubbles with larger diameters and the uneven distribution of bubble sizes formed along the microporous sparger. This phenomenon occurred due to the conjunction of bubbles that had been formed earlier. Otherwise, the bubbles formed would be smaller and more evenly distributed. Single loop fluidic oscillators can generate smaller bubbles than double loop fluidic oscillators based on this research data.

\section{ACKNOWLEDGEMENT}

The authors would like to thank the Ministry of Research, Technology and Higher Education of Republik Indonesia (KEMENRISTEK-DIKTI RI) for funding this research for the Masters program toward a Doctorate for Superior Bachelor (PMDSU) 2019 with contract number NKB1862/UN2.R3.1/HKP.05.00/2019. 


\section{REFERENCES}

Budhijanto, W. ,Deendarlianto, K. H., Satriawan, D., 2015. Enhancement of Aerobic Wastewater Treatment by the Application of Attached Growth Microorganisms and Microbubble Generator. International Journal of Technology, Volume 6(7), pp. 1101-1109

Deendarlianto, D., Tontowi, A.E., Indarto, A.G.W.I. ,Iriawan, A., 2015. The Implementation of a Developed Microbubble Generator on the Aerobic Wastewater Treatment. International Journal of Technology, Volume 6(6), pp. 924-930

Hanotu, J., Kong, D., Zimmerman, W.B., 2016. Intensification of Yeast Production with Microbubbles. Food and bioproducts processing, Volume 100 pp. 424-431

Hidayat, A., Mukti, N.I.F., Handoko, B., Sutrisno, B., 2018. Biodiesel Production from Rice Bran Oil Over Modified Natural Zeolite Catalyst. International Journal of Technology, Volume 9(2), pp. 400-411

Juwana, W.E., Widyatama, A., Dinaryanto, O., Budhijanto, W., 2019. Hydrodynamic Characteristics of the Microbubble Dissolution in Liquid using Orifice Type Microbubble Generator. Chemical Engineering Research and Design, Volume 141 pp. 436-448

Lye, G., Stuckey, D., 2001. Extraction of Erythromycin-A using Colloidal Liquid Aphrons: Part II. Mass Transfer Kinetics. Chemical Engineering Science, Volume 56(1), pp. 97-108

Makuta, T., Takemura, F., Hihara, E., Matsumoto, Y., Shoji, M., 2005. Generation of Micro Gas Bubbles of Uniform Diameter in an Ultrasonic Field (2nd Report, the Conditions of the Stable Generation of Micro Gas Bubbles of Uniform Diameter in an Ultrasonic Field). Nihon Kikai Gakkai Ronbunshu, B Hen/Transactions of the Japan Society of Mechanical Engineers, Part B, Volume 71(710), pp. 2465-2470

Pham, M.T., Hoang, A.T., Le, A.T., Al-Tawaha, A., Dong, V.H. ,Le, V.V., 2018. Measurement and Prediction of the Density and Viscosity of Biodiesel Blends. Int. J. Technol, Volume 9(5), pp. 1015-1026.

Rahman, A., Prihantini, N. B. ,Nasruddin., 2019. Fatty Acid of Microalgae as a Potential Feedstock for Biodiesel Production in Indonesia. In: AIP Conference Proceedings, AIP Publishing

Rehman, F., Medley, G.J., Bandulasena, H., Zimmerman, W.B., 2015. Fluidic OscillatorMediated Microbubble Generation to Provide Cost Effective Mass Transfer and Mixing Efficiency to the Wastewater Treatment Plants. Environmental research, Volume 137 pp. 32-39

Spyropoulos, C.E.A Sonic Oscillator., 1964. Proceeding Of The Fluid Aplication Symposium. Proceedings, US Army Material Command, Harry Diamond Laboratories

Tesař, V., 2014. Shape Oscillation of Microbubbles. Chemical Engineering Journal, Volume 235 pp. 368-378

Tesař, V., Peszynski, K., 2013. Strangely Behaving Fluidic Oscillator. In: EPJ Web of Conferences,. EDP Sciences

Warren, R.W., 1964. Negative Feedback Oscillator. Google Patents

Zheng, Q., Xu, X., Martin, G. J. ,Kentish, S. E. 2018. Critical review of strategies for CO2 delivery to large-scale microalgae cultures. Chinese journal of chemical engineering, Volume 26(11), pp. 2219-2228

Zimmerman, W.B., Tesar, V., Butler, S., Bandulasena, H.C., 2008. Microbubble Generation. Recent Patents on Engineering, Volume 2(1), pp. 1-8

Zimmerman, W.B., Zandi, M., Bandulasena, H.H., Tesař, V., Gilmour, D.J., Ying, K., 2011. Design of an Airlift Loop Bioreactor and Pilot Scales Studies with Fluidic Oscillator Induced Microbubbles for Growth of a Microalgae Dunaliella Salina. Applied Energy, Volume 88(10), pp. 3357-3369 